\section{Public policy and the social determinants of health: the challenge of the production and use of scientific evidence}

\author{
Políticas públicas e determinantes sociais da \\ saúde: o desafio da produção e uso das \\ evidencias científicas
}

Alberto Pellegrini Filho 1

It has long been known that the distribution of health and disease in populations is not at random, but obeys the socioeconomic stratification of population groups. In the mid-nineteenth century authors such as Villermé (1782-1863) in France, Chadwick (1800-1890) and Engels (1820-1895) in England observed a clear association between high mortality and poverty. Although these authors share similar findings, they differ regarding the causes and solutions. ForVillermé, poverty and addictions are the cause of diseases and, for him, the solutions were found in the strengthening of morals and a laissez-faire economy. Chadwick, emphasizing the importance of the environment, considered that filth and immorality cause disease and poverty and proposed measures to control the environment such as access to clean water, sanitation and garbage disposal. Engels argued that capitalism and class exploitation produce poverty, disease and death and the only solution to fight them would be the socialist revolution 1 .

Virchow (1821-1902), considered the father of social medicine (though he did not coin this term), affirmed that "medical science is intrinsically and essentially a social science", that "the economic and social conditions have an important effect on health and disease and that such relations should be subject to scientific research" 2 (p. 80) and that "the very term public health expresses its political character and its practice and should necessarily lead to intervention in social and political life to 
identify and remove obstacles that undermine the health of a population" 2 (p. 83).

Throughout the twentieth century much progress was made in the study of these relationships, particularly between working and living conditions and health situations, while social epidemiology in Latin America has made an important contribution to the study of the social determinants of the health-disease process in the various countries of the region ${ }^{3}$.

The Constitution of the World Health Organization (WHO) in 1948, recognizing that health is a state of complete physical, mental and social wellbeing and not merely the absence of disease, confirms the importance of social determinants of health. Later, the Conference of Alma-Ata in 1978 and the Ottawa Charter of 1986 reiterate this approach. The Ottawa Charter affirms that "the fundamental conditions and resources for health are peace, housing, education, food, income, stable ecosystem, sustainable resources, social justice and equity" (http://bvsms.saude.gov.br/bvs/pub licacoes/cartas_promocao.pdf, accessed on 05/ Apr/2011).

With this background and knowledge accumulated over many years, it is worth asking what is new in this current global movement around the social determinants of health, led by the WHO since the creation of the Commission on Social Determinants of Health (CSDH) in 2005 with its Brazilian counterpart represented by the National Commission on Social Determinants of Health.

A distinctive feature of this current movement is the explicit commitment to action, based on the idea that the social determinants of health are the product of human action and that their transformation could and must be subject to human action, organized through intersectoral public policies based on evidence and implemented with the support and participation of broad segments of society. The three basic recommendations of the $\mathrm{CSDH}$ report are: improving living conditions, addressing the inequitable distribution of power, money and resources and measuring the problem and assessing the impact of action. The recommendations capture well the technical, political and social aspects of this commitment.

This confidence in transformative action overcomes fatalistic conceptions about the social determinants of health. According to these conceptions, the health status of an individual or a group is definitively shaped by their social position. On the contrary, the recognition that historical and social processes are the result of a dialectical tension between determinism and freedom of human decisions or choices underlies this current movement around the social determinants of health 4 . In conclusion, this movement is not just more of the same, but a combination of new tools, methodologies and approaches that offer a new energy to public health committed to the fight against the enormous, avoidable and unjust inequities that persist in societies like ours.

As already mentioned, public policies to combat health inequities through action on the social determinants of health in the context of this new movement around social determinants of health should be firmly supported through three pillars:

- Scientific evidence that identify the mechanisms through which the basic causes produce health inequities, and thereby inform us where and how to intervene to reduce these inequities;

- Intersectoral coordination for joint efforts from various sectors related to the social determinants of health, as well as different levels of government (federal, state, municipal) and different powers of the State (executive, legislative and judiciary);

- Broad social participation to ensure political support for the redistribution of power and resources.

In this introductory article of a special issue of the Cadernos de Saúde Pública dedicated to presenting research results on the social determinants of health, we will make some considerations about the first of these pillars, namely the production and use of scientific evidence for policies.

First of all, it is worth noting that the term scientific evidence is an oxymoron. Evident is what is manifest, visible, irrefutable. A piece of information or knowledge cannot be regarded as scientific if it is irrefutable, since the possibility of being refutable is an essential feature of a scientific fact. Regarding evident as what is manifest and visible, the role of science is precisely to discover what is hidden by the appearances of the manifest and visible. However, the term "scientific evidence" is widely adopted and it will be used hereafter.

It is possible to identify three generations of studies about the relationships between the social determinants of health and health. A first generation, which began in the nineteenth century, focused on the analysis of relationships between poverty and health. A second generation is characterized by the identification of health gradients according to socioeconomic stratification. Current research efforts focus on studying the ways in which social determinants of health produce health inequities between social groups. The current main research questions are: "Where do health inequities among social groups originate?"; "What are the pathways from root causes to health inequities?"; "Where and how should we intervene to reduce health inequities?" 5 . 
The answer to these questions is pursued by studies based on different conceptual, theoretical and methodological approaches: the materialist / structuralist model suggests that inadequate levels of income lead to a lack of resources for dealing with stressors, producing disease; the social capital model emphasizes the deterioration of social relations as a mediator between socioeconomic inequality and health outcomes; the psychosocial model proposes that discrimination based on position in the social hierarchy creates stress which in turn produces a neuroendocrine response that causes disease; the social production of health model is based on the premise that the capitalistic priorities to accumulate wealth, power, prestige and material goods are made at the expense of the dispossessed; the ecosocial model combines psychosocial and social production of health models, seeking to understand how social and physical environments interact with biology and how individuals incorporate in their own bodies elements of the contexts in which they live and work, including the concept of collective lifestyle, according to which the choices of lifestyles are influenced by the environment in which people live 6,7 .

Whatever the conceptual and methodological approaches, the results of research devoted to the study of the relationships between health and its determinants must produce scientific evidence that serves to support policies and interventions on social determinants of health. The use of evidence for decision making in health has been proposed by clinical medicine since the 1970s. The movement "evidence based medicine" was created, based on principles established by the seminal work of Cochrane ${ }^{8}$. According to Sackett et al. 9 , evidence based medicine is defined as the conscious, explicit and judicious use of the best evidence to make decisions about the care of individual patients. The practice of evidencebased medicine is the integration of individual clinical experience with the best available external clinical evidence produced by scientific research. Evidence based medicine allows both to invalidate diagnostic tests and treatments previously accepted and to replace them with more powerful, effective and safe ones and is based on systematic reviews of the literature promoted by an international network called the Cochrane Collaboration (http://www.cochrane.org/) established in 1993. So far 4,000 Cochrane reviews were published online by the Cochrane Library (which can be accessed at http://evidences.bvsa lud.org/php/index.php?lang=pt).

Despite the careful quantitative comparisons of benefits and harms of certain practices that underlie evidence based medicine, its widespread adoption is still problematic. In fact, it is not easy to persuade health professionals to abandon traditional practices that have been shown to be ineffective or harmful in light of the scientific evidence gathered through systematic literature reviews. Nor is it easy to convince them to adopt new practices whose efficacy and effectiveness is fully supported by repeated studies.

These difficulties are much greater when it is intended to adopt a similar approach to implement evidence-based social policies aimed at promoting equity in health. In continuation some of the main difficulties of this adoption are highlighted.

The first refers to the criteria and methodology to generate evidence on population-based public policies. In the case of evidence based medicine, since the 1970s a clear hierarchy of evidence was established to infer the effectiveness of a given medical intervention. Findings in Randomized Controlled Trials (RCT) are considered the most reliable, better than observational studies and much better than the opinions of experts. However, the use of RCT for the evaluation of interventions at community level presents several difficulties. Braveman et al. 10 provide an exhaustive list of these difficulties. What follows is a summary of this list:

- The documentation of the effects of social determinants of health and of the interventions on them in the health of populations presents great difficulties, particularly when it comes to the socalled distal social determinants of health. Unlike the proximal determinants such as poor nutrition or inactivity, that exhibit most direct and immediate effects, the causal relationships between distal social determinants of health (employment, income, etc.) and health involve complex mediations between several social factors that can interact with each other and with biological factors, making it more difficult to study the effectiveness of social interventions;

- The complex relationships between social determinants of health and health outcomes can take decades to manifest, with important implications in terms of feasibility and costs for research dedicated to the evaluation of interventions, especially with the RCT methodology;

- The RCTs usually involve relatively small samples of specific populations and settings making it difficult to generalize their results. They usually do not have adequate information about the context, which is crucial to judge whether the intervention submitted to the assessment can be effectively implemented in other populations or settings 11 ;

- The implementation of a social intervention at community level requires the mobilization 
of political will and can affect various interest groups. For this reason a random distribution of who receives the intervention or not is often unfeasible. Moreover, it is almost impossible to avoid exposure by control group as in the case, for example, of advertising campaigns to promote healthy habits;

- The quality of an RCT in the clinical area is valued for its standardization, consistency and fidelity. In the case of research at the community level, however, variation is usually inevitable or even desirable, because interventions must be tailored to the needs, capacities and priorities of each community to achieve greater effectiveness.

The authors cited 10 concluded that the attention to accuracy emphasized by the evidence based medicine movement should be preserved in case of interventions on social determinants of health. However, for the reasons already stated, RCTs are not always ethical, feasible or desirable in the case of such interventions and cannot be adopted as the "gold standard" for evaluation. This implies the need to adopt a broader and more diverse range of sources and methods equally rigorous.

Apart from problems related to conceptual and methodological aspects for the generation of evidence, their application to policy and interventions on social determinants of health also face difficulties of another order, some of which follow 12 :

- Unlike clinical practice, where there is a relatively abundant critical mass of studies evaluating procedures, drugs and technologies, the number of studies on the impact of interventions on social determinants for promoting equity in health is markedly lower. This was clearly observed during the preparation of the report of the National Commission on Social Determinants of Health 13 which was facilitated by the wealth of Brazilian scientific production on the relationship between social determinants of health and health, although the same wealth has not been observed in the case of evaluation of interventions (the bibliography of the Report with some 400 references is available at http:/ / search. bvsalud.org/dss/?where=DSS);

- Research subjects in clinical studies are in general defined in close collaboration between researcher and health professional who quite often end up being the same person. In the case of public policies related to social determinants of health, however, research subjects are usually defined by the researcher, with little or no participation of the actors involved in the decision making process of those policies;

- The locus of knowledge production and the locus of its use in clinical practice are often the same, as well as its actors. These spaces are much more distant and differentiated in the case of social policies, along with other barriers of language, culture and values;

- The research results and systematic reviews of procedures and technologies in clinical practice in general result in specific indications for its application. That is not the case in public policies related to complex issues such as poverty, environmental degradation and others, where such results indicate a possible range of interventions whose selection is often done with criteria and mechanisms of a political nature, involving multiple actors;

- Given the similarity of the clinical picture and the similarity of the impact of clinical procedures in different contexts, the interventions in clinical practice have a more universal character, facilitating the transfer of experiences. By contrast, in the case of public policies related to social determinants of health, the diversity of local settings and the importance of context for assessing the impact of interventions make it difficult to transfer experiences. In fact, the results of research and reviews in such interventions are specific to a particular context, always posing the question of replicability, ie, to what extent the findings in a given setting can be replicated if the interventions are implemented in a different context;

- Health professionals have relative autonomy to make decisions about patient care and the difficulties of adopting evidence-based medicine in most cases are due to a possible conflict between the individual clinical experience and results of systematic reviews. In the case of public policies related to social determinants of health the decision-making process is much more complex and often implies the redistribution of power and resources, involving the participation of different actors with different interests using different criteria to base their decisions.

Taking into consideration the difficulties mentioned above, the strategies to promote the use of evidence in public policy related to the social determinants of health should be diverse and adequate to different situations. Among them should be included:

- Definition of a core set of indicators to monitor trends in health inequities and to assess the impact of policies and programs to combat them. The operation of this set of indicators and analysis of trends should be the responsibility of instances that lie at the interface between the institutions that produce information and those that are responsible for the decision making process. These instances, so-called Observatories, in the definition of Gattini 14 (p. 11) are seen as " $a$ policy-oriented virtual-based national center aimed 
at performing systematic and ongoing observation on relevant issues about population health and health systems, in support of effective and evidence-based health policy, planning, decisionmaking and action in public health and health systems. The ultimate goal is to contribute to the preservation and improvement of the health of the population, including the reduction of inequities". - Promotion of an increase in critical mass and decentralization of studies for the evaluation of interventions, as well as improving of their methodology. An increase in systematic reviews on interventions and policies to promote social equity such as those promoted by the Campbell Collaboration, an initiative similar to the Cochrane Collaboration, which conducts systematic reviews on the effects of social interventions in areas such as education, justice and social policies and services (available in http://www.campbellcol laboration.org/);

- Change the way the research agenda and research priorities are set. They should be defined with a view to solving problems, through mechanisms and spaces of interaction that involve both researchers and users of knowledge, as is the case of the so-called "contexts of application" 15;

- Promotion of collaborative networks among institutions of various types that involve researchers, managers, decision makers and other professionals for establishing the research agenda, development of research process and analysis of policy implications of research results;

- Expansion of the criteria and mechanisms for validation of knowledge, including both scientific merit and social relevance with the participation of "peers" and "non-peers";
- Diversification of the means for dissemination of knowledge that should not be confined to scientific journals in order to achieve the various actors of the decision-making process. As already mentioned, the decision making process in public policy, particularly regarding the combat of inequities involves several actors. Therefore, the pursuit for greater use of information and knowledge in this process involves making them accessible through media and formats appropriate to the different actors involved and not just the so-called decision makers. Furthermore, the reduction of inequities in access to knowledge and information might itself contribute to reducing health inequities, since the inequities of information are an important determinant of health inequities as they hinder the individual and collective action of members of a society to change structures, behaviors and policies 16 .

It is essential to overcome the difficulties identified to ensure greater use of scientific evidence obtained through rigorous methods both to define and implement social interventions and to evaluate its effects on health. Along with better coordination of efforts of the sectors involved and a stronger social participation, the use of scientific evidence should help to ensure that social policies respond to increasing demands for better allocation of public resources in policies and programs with proved effectiveness.

\section{Resumo}

Este artigo tem um caráter introdutório aos demais publicados neste número temático de Cadernos de Saúde Pública. O autor faz uma revisão histórica dos conceitos, enfoques e metodologias utilizados para o estudo das relações entre os determinantes sociais e a situação de saúde. Ao analisar o atual movimento global em torno dos determinantes sociais da saúde considera que seu traço distintivo é o explícito compromisso com a ação através de políticas públicas intersetoriais baseadas em evidências e implantadas com o apoio e participação de amplos segmentos sociais. Como este número temático dos Cad Saúde Pública se dedica a apresentar os resultados de pesquisas relacionadas aos determinantes sociais e saúde, o autor se concentra na análise das dificuldades para a produção e utilização de evidências científicas que fundamentem a definição, implantação e avaliação de políticas de combate às iniquidades em saúde através da ação sobre os determinantes sociais e saúde. Para concluir, apresenta algumas recomendações para a superação dessas dificuldades.

Políticas Públicas; Política Social; Indicadores Sociais; Avaliação 


\section{References}

1. Birn AE. Historicising, politicising and futurising; closing the gap in one generation: health equity trough action on the social determinants of health. In: Bhattacharya S, Messenger S, Overy C, editors. Social determinants of health: assessing theory, policy and practice. New Delhi: Orient Blackswan Private Limited; 2010. p. 76-113.

2. Rosen G. Da polícia médica à medicina social. Rio de Janeiro: Edições Graal; 1980.

3. Almeida Filho N, Kawachi I, Pellegrini Filho A, Dachs N. Research on health inequalities in Latin America and the Caribbean: bibliometric analysis (1971-2000) and descriptive content analysis (1971-1995). Am J Public Health 2003; 93:2037-43.

4. Ramos AG. A modernização em nova perspectiva: em busca do modelo da possibilidade. In: Heidemann FG, Salm JF, editors. Políticas públicas e desenvolvimento: bases epistemológicas e modelos de análise. Brasília: Editora UnB; 2009. p. 41-79.

5. Adler N. NIH Conference on understanding and reducing disparities in health: behavioral and social sciences research contributions. http://obssr. od.nih.gov/news_and_events/conferences_and_ workshops/HealthDisparities/images/Health\%20 Disparities\%20Final.pdf (accessed on 05/Apr/ 2011).

6. Kelly MP, Morgan A, Bonnefoy J, Butt J, Bergman $\mathrm{V}$. The social determinants of health: developing an evidence base for political action. Final report to World Health Organization/Commission on the Social Determinants of Health. http://www.who. int/social_determinants/resources/mekn_final_ report_102007.pdf (accessed on 05/Apr/2011).

7. Bonnefoy J, Morgan A, Kelly MP, Butt J, Bergman V. Constructing the evidence base on the social determinants of health: a guide. http://www.who. int/social_determinants/knowledge_networks / add_documents/mekn_final_guide_112007.pdf (accessed on 05/Apr/2011).
8. Cochrane AL. Effectiveness and efficiency: random reflections on health services. London: Nuffield Provincial Hospitals Trust; 1972.

9. Sackett DL, Rosenberg WMC, Gray JAM, Haynes RB, Richardson WS. Evidence based medicine: what it is and what it isn't [Editorial]. BMJ 1996; 312:71.

10. Braveman PA, Egerter SA, Woolf SH, Marks JS. When do we know enough to recommend action on the social determinants of health? Am J Prev Med 2011; 40(1 Suppl 1):S58-66.

11. Victora CG, Habicht JP, Bryce J. Evidence-based public health: moving beyond randomized trials. Am J Public health 2004; 94:400-5.

12. Pellegrini Filho A. Compromisso com a ação. Radis 2006; (47):12-4.

13. Comissão Nacional sobre Determinantes Sociais da Saúde. As causas sociais das iniquidades em saúde no Brasil. Rio de Janeiro: Editora Fiocruz; 2008.

14. Gattini $\mathrm{CH}$. Implementing national health observatories: operational approach and strategic recommendations. Santiago: Pan American Health Organization/World Health Organization; 2009. (Technical Series on Information for Decision Making).

15. Gibbons M, Limoges C, Nowotny H, Schwartzman S, Scott P, Trow M. The new mode of production of knowledge. London: Sage Publications; 1994.

16. Pellegrini Filho A. Inequidades de acceso a la información e inequidades de salud. Rev Panam Salud Pública 2002; 11:409-13.

Submitted on $01 / \mathrm{Mar} / 2011$

Approved on 28/Mar/2011 